\title{
DEVELOPMENT OF AN EASY AND EFFECTIVE ATTACHMENT SYSTEM FOR LOWER LIMB PROSTHESIS
}

\author{
Andreia S. Silveira ${ }^{1}$, Patrícia A. Senra ${ }^{2}$,Eurico Seabra ${ }^{3}$, Luís F. Silva 4 \\ 1,2,3,4 Department of Mechanical Engineering, Guimarães, Portugal, \\ A68374@alunos.uminho.pt,_a61758@alumni.uminho.pt, \\ seabra@dem.uminho.pt,lffsilva@dem.uminho.pt
}

\begin{abstract}
This study aimed to introduce a new suspension system that is capable of increasing the amputee's satisfaction in terms of locking the residual limb inside the prosthetic socket. This paper describes the design and development phases carried out to optimize the final solution. The design system was based on the amputee's needs and the requirements of prosthetic suspension systems. The final solution is a combination of a guiding and fixation system, to overcome some of the reported problems with the current systems, presenting a new simple suspension method that improves the donning and doffing of prosthesis. The new suspension system is a good alternative system to improve the life quality of amputees with lower activity level on the daily basis and, consequently, ease their rehabilitation.
\end{abstract}

Keywords: Suspension System, Mechanical Design, Guiding System, Locking System, Lower Limb Prosthesis.

\section{Introduction}

Lower-limb amputation is one of the oldest known surgically performed procedures, due to trauma, vascular disease, congenital malformations and tumours [1]. People with lower limb amputation (LLA) relies on prosthetics to replace the lost limb functions, pinpoint as a crucial element in rehabilitation [2].

Prosthetic rehabilitation is a field in exponential expansion as a result of technological innovations. Different types of prostheses have been developed in an attempt to mitigate the difficulties of people with LLA experience on a daily basis [3].

Even with a well-performed amputation and a well-fitted prosthesis, some patients have persistent symptoms of residual extremity pain, tissue breakdown and a sense of instability [4]. Many of these problems are associated with poor prosthesis fitting and suspension system since they are strongly related to the functional efficiency and comfort level of the prosthesis [5].

Suspension system is an imperative component for a successful rehabilitation since it connects firmly the socket to the residual limb in order to prevent the excessive movements between them [6]. Several prosthetic suspension systems are commercial available, including pin/lock systems, suction and vacuum systems, silesian belt, hip joint with pelvic band and recently magnetic system [5,6]. Each method may have disadvantages and advantages depending on the type of user.
Pin/lock systems links a soft liner to the socket via a distal stainless steel pin attached to the distal end of the liner. This secure and simple method permits a quick and easy donning and doffing for all the users [7]. In spite of the overall satisfaction, the pin/lock system is associated with pain at the distal residual limb and discoloration of the distal tissues and in long-term it can sometimes develop into verrucous hyperplasia [8]. Prosthetists attribute these symptoms to the pistoning mainly observed during swing phase and milking phenomenon $[7,9]$. The external pressures applied to the residual limb compromised the skin health since the tissues were not designed to support these stresses [8].

In contrast, both vacuum and suction suspension systems decrease the pistoning effect $[5,10]$. In fact, uses the differential air pressure as a force to hold on the prosthesis to the residual limb, creating a better fit inside the socket [9]. Suction suspension creates a negative air pressure by using a passive expulsion valve to expel the air from the socket when the limb begins to move. In other hand, vacuum suspension does not depend upon the limb position to expel the air. Instead uses an active pump to generate a high-level vacuum, increasing surface contact with the socket wall [11]. These systems provide more stable residual limb volume and improve comfort. However, both systems are more expensive and cause discomfort in terms of donning and doffing than suspension alternatives and it is not recommended for users with high residual limb volume fluctuations since socket fit and suspension will diminish [12,13]. An alternative is the 
suspension method described in Eshraghi et al., 2013 which uses a magnetic-based coupling system to reduce the pressures within the socket particularly during the swing phase of gait [14].

The selection between the commercial solutions requires a careful evaluation in order to choose the suspension system that best adequate the needs of amputees. This report presents a mechanism based on the difficulties that elderly population have with the prosthesis during the daily basis, since they have the highs incidence of LLA. While the commercially suspension systems are focus on decreasing the pistoning effect, this new approach intends to increase life quality of amputees, by designing a simple suspension method that improves the donning/doffing of the prosthesis.

\section{Suspension System Design}

The proposed suspension system was development as the best solution between different possibilities. To select the final solution, it was established the amputee's needs and applied the mechanical design tools, such as the function diagram and morphological map.

\section{- Motivation}

User/customer's perspective appears in Engineering Design as the "customer need" concept, defining that product development should have in mind the customer and market needs [15].

During the product development, it was carried out an evaluation of the needs that amputees have with pin/lock systems since it is a suspension system commonly used among the amputees.

Lower limb amputations are increasingly due to incidence of vascular diseases, such as diabetes, especially affecting the older population [16].
So, the mainly user was defined has a person with lower level of activity and manual dexterity and presents difficulties in terms of adaptation and learning, since most of them have advanced age.

In fact, even though the pin/lock system is a simple mechanism, it can be challenging for amputees with poor hand dexterity in terms of inserting the pin correctly into the housing, which in the long term can cause deformation of the pin and housing, limb volume variations and pain at the end of distal limb. Therefore, it was essential to take into account the effective pin insert, as well as the simplicity of design as important needs, to decrease the restrictions between the system and user.

\section{- Design and development}

The mechanical design of the suspension system was driven by the need to guide the fixing element into the housing. It ensures that the fixing element is inserted correctly into the housing without colliding at the its ends and, at the same time, increases the amputee's satisfaction in terms of donning and doffing. The other parameters that were also taken into account are as follows: safety, comfort, ergonomics, easy to handle, aesthetic appearance and cost.

Briefly, this mechanism has two mainly functions: guide the fixing element into the housing and establish a firm attachment between the residual limb and the prosthesis by attaching the fixing element. The diagram shown in Fig. 1, represents the functions established for the proposed mechanism, as a quick and easy process of donning and doffing of the prosthesis.

The final solution contemplates the specifications shown in the Table 1, to avoid any conceptual problems such as inadequate dimensions and unnecessary costs.

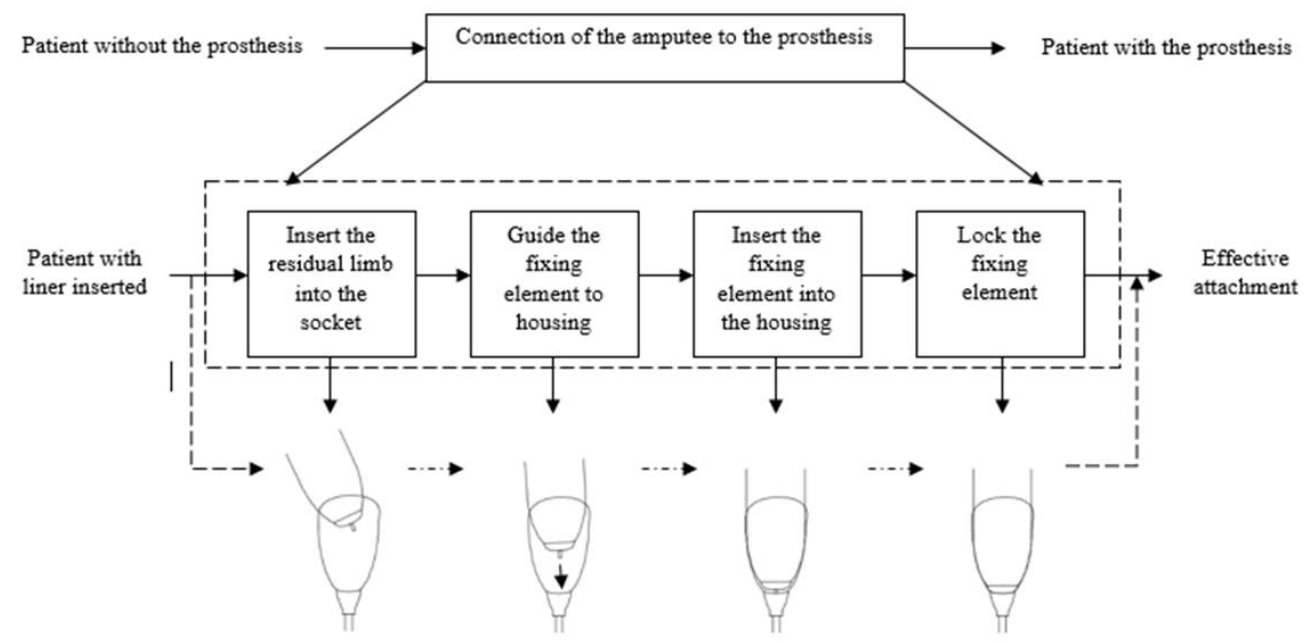

Figure 1: Schematic diagram of the functions of the proposed mechanism to attach the residual limb to the prosthesis 
Table 1. Suspension mechanism specifications

\begin{tabular}{|c|c|}
\hline Design & Performance \\
\hline $\begin{array}{l}\text { - Lower height, } \\
\text { with a maximum } \\
\text { limit of } 44 \mathrm{~mm} \text {; } \\
\text { - A mechanism } \\
\text { feasible for all } \\
\text { types of patients } \\
\text { until the } 100 \mathrm{kgf} \text {; } \\
\text { - The structure of } \\
\text { liner and socket } \\
\text { cannot be } \\
\text { modified. }\end{array}$ & $\begin{array}{l}\text { - Simple, rigid and } \\
\text { secure attachment; } \\
\text { - Properly alignment of } \\
\text { the fixing element } \\
\text { into the entrance of } \\
\text { the housing; } \\
\text { - Ensure an efficient } \\
\text { locking system; } \\
\text { - Simple and easy } \\
\text { donning and doffing; } \\
\text { - Ensure an } \\
\text { appropriate for the } \\
\text { mechanism for } \\
\text { recent amputees. }\end{array}$ \\
\hline
\end{tabular}

To achieve these functions, different suspension designs were proposed - Fig. 2 schematically illustrates the proposed designs solutions in a morphological chart. The decision process involved the selection of subsolutions that best suited the previously defined requirements and specifications to implement the subfunctions. The proposed system mechanism is a combination of the subsolutions iii, viii and xii. The final solution is a merge of the ALPS Lock S496-T commercial system (fixing mechanism) with a retractable wire mechanism (guiding mechanism).

\section{- Mechanism design}

The obtained suspension mechanism, as shown in Fig. 3 (a) and (b), consists of a stainless steel serrated pin, a guiding and a fixation mechanism.

Guiding mechanism

The proposed guiding mechanism is shown in Fig. 4. The guiding mechanism was divided into two function phases, pulling and retracting the nylon wire in order to guide the pin until the housing: (1) In the first phase, the nylon wire is pulled up to the distal area of residual limb and it is connected to the end of the pin through a nut at the end of the wire. The pulling of the nylon wire causes the movement of the spool towards the counter clockwise direction and the roller (d) moves in the curved trough. The applied force on the nylon wire, through the movement of the residual limb, causes deformation on the spring inside the spool.

The second phase occurs when the force applied on the nylon wire is removed. With the release of the pulling, the roller moves to the cavity and locks the spool movement. A slight pulling of the wire clears the roller from the cavity and it no longer prevents the spring of going back to its initial position. Consequently, the spool moves in a clockwise direction and the nylon wire is collected into the reel.

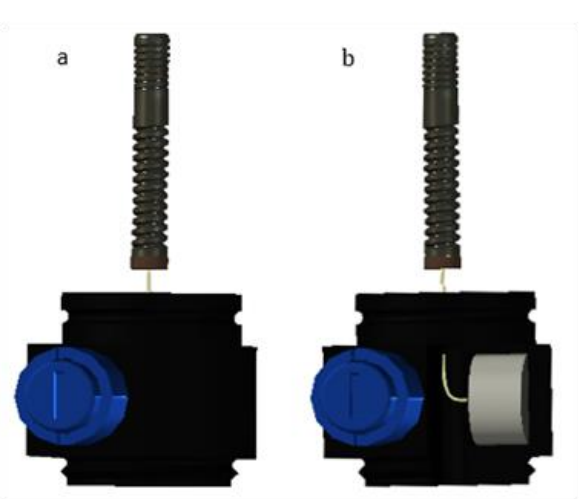

Figure 1: The designed suspension system: (a) front view, and (b) inside detail

The guiding mechanism includes a spring, a nylon wire, a screw, a roller and a spool inside the reel. The spool has an external and internal compartment and it is assembled around the spindle of the housing. The nylon wire is stored in the external compartment of the spool. One of the ends of the wire is attached to the spool and the other end is outside of the housing and it is connected to a nut.

The distance that the nut engaged the pin corresponds to the maximum length of the nylon wire, $400 \mathrm{~mm}$. The spring located in the inside compartment is a constant-force spring, with one end fixed to the spindle and the other end to the spool. The nylon wire has good resistance to fatigue, abrasion and torsion. These properties are the key for a suitable functioning of the system, since the wire is under tension.

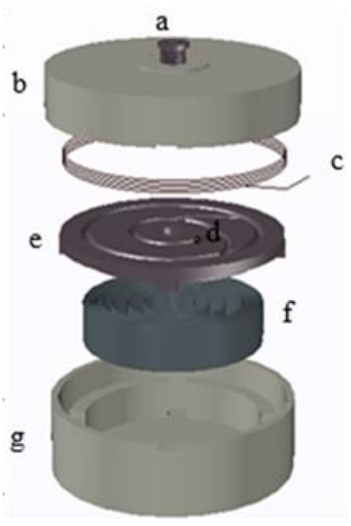

Figure 2: Overview of the guiding system mechanism with (a) screw, (b) top part of the reel, (c) nylon wire, (d) bearing, (e) top part of the spool, (f) spring and (g) bottom part of the reel and spool

\section{- Fixation mechanism}

The fixation mechanism shown in Fig. 5, consists of a one-way gear rotation mechanism. The rotation of the gear allows the pin to get inside the housing and the teeth of the gear engage with the serrated pin. In turn, the HFL0822 INA needle clutch bearing in juxtaposition with the gear inhibits the rotation in the opposite direction. 
Since the gear mechanism only rotates in one direction, the pin keeps engaged and cannot be removed from the housing until the push button is pressed.

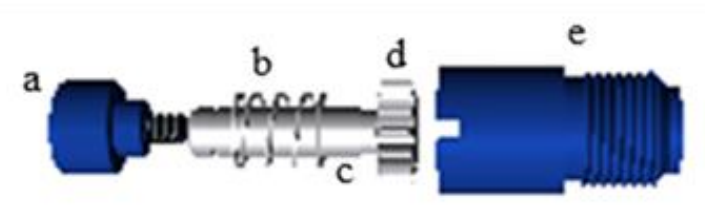

Figure 3: Overview of the fixation mechanism with the

(a) push button, (b) spring, (c) HFL0822 INA needle clutch, (d) pinion gear and (e) clutch housing

The locking mechanism contains a screw attached to push button, a spring, a clutch housing, a HFL0822 INA needle clutch bearing and a pinion gear.

Both mechanisms are stored inside the housing. The housing is made of nylon, reinforced with fibreglass, it contains a vertical hole that slightly intersects with horizontal hole. The upper portion of the vertical hole has a cone-shaped form to receive the pin. The horizontal hole has internal threads and receives the locking mechanism that allows the engage and disengage of the pin.

The clutch housing has a threaded part that it is screwed into the horizontal hole. The other part remains outside the housing and at its end the push button is assembled. The pinion gear is assembled inside the clutch housing with the pinion head located at the end of the threaded part. The pinion teeth engage with the serrated pin when it is inserted.

The HFL0822 INA needle clutch bearing is incorporated in the threaded part of the clutch housing and it is assembled in juxtaposition with the pinion gear, in order to promote the unidirectional movement of the gear and prevent the retraction of the pin. The compression spring positioned between the push button and the HFL0822 INA needle clutch bearing is in juxtaposition with the gear. So, when the push button is pressed, the spring is compressed and the gear moves along the longitudinal axis of the housing. Consequently, the pinion teeth are no longer engage with the serrated pin and, therefore, it is possible to remove the pin from the housing. Besides removing the pin when the push button is pressed, it is also possible to manually rotate the push button, since the button is screwed at end of the gear; the pinion gear rotates with the rotation of the push button in the direction that allows the pin to enter inside the housing.

\section{Conclusions}

The study herein presented revealed that this new suspension system is suitable for the amputees. The proposed mechanism is a good alternative for elderly amputees, since it can solve some of the problems they experience on a daily basis with the current systems. It provides an easy donning and doffing at the same time, ensuring a firm attachment to the socket and presenting lower weight and cost.

However, it is still necessary further research to full evaluate the performance of the proposed mechanism. In future, this system will be compare with prosthetic suspension systems available in the market, in terms of patient's satisfaction. Also, finite element analyses will be carried out to examine the maximum loads that the system can support, and systematic tests should be carried out to determine the real benefits and advantages of the proposed system.

\section{References}

[1] Fiedler, G., Akins, J., Cooper, R., Munoz, S. and Cooper, R. A. (2014). "Rehabilitation of People with Lower- Limb Amputations", Current Physical Medicine and Rehabilitation Reports, vol. 2(4), pp.263-272.

[2] Penn-Barwell, J. G. (2011). "Outcomes in lower limb amputation following trauma: A systematic review and meta-analysis", Injury, vol. 42(12), pp.1474-1479.

[3] Andrysek, J. (2010). "Lower-Limb Prosthetic Technologies in the Developing World: A Review of Literature from 1994-2010", Prosthetics and Orthotics International, vol. 34(4), pp.378-398.

[4] Safari, M. R. and Meier, M. R. (2015). "Systematic review of effects of current transtibial prosthetic socket designs-Part 1: Qualitative outcomes", Journal of Rehabilitation Research \& Development, vol. 52(5), pp.491-508.

[5] Gholizadeh, H., Osman, N. A. A., Eshraghi, A. and Ali, S. (2014). "Transfemoral Prosthesis Suspension Systems A Systematic Review of the Literature Transfemoral Prosthesis Suspension Systems", American Journal of Physical Medicine \& Rehabilitation, vol. 93(9), pp.809-823.

[6] Gholizadeh, H., Osman, N. A. A., Eshraghi, A., Ali, S. and Yahyavi, E. S. (2013). "Satisfaction and Problems Experienced with Transfemoral Suspension Systems: A Comparison Between Common Suction Socket and Seal-In Liner", Archives of Physical Medicine and Rehabilitation, vol. 94(8), pp.1584-1589. 
[7] Eshraghi, A., Azuan, N., Osman, A., Karimi, M. and Ali, S. (2012). "Pistoning assessment in lower limb prosthetic sockets", Prosthetics and Orthotics International, vol. 36(1), pp.15-24.

[8] Beil, T. L. and Street, G. M. (2004). "Comparison of interface pressures with pin and suction suspension systems", Journal of Rehabilitation Research \& Development, vol. 41(6), pp.821-828.

[9] Eshraghi, A., Abu Osman, N. A. A., Karimi, M. T., Gholizadeh, H., Ali, S. and Wan Abas, W. A. B. (2012). "Quantitative and Qualitative Comparison of a New Prosthetic Suspension System with Two Existing Suspension Systems for Lower Limb Amputees", American Journal of Physical Medicine \& Rehabilitation, vol. 91(12), pp.10281038.

[10] Klute, G. K., Berge, J. S., Biggs, W. and Pongnumkul, S. (2011). "Vacuum-Assisted Socket Suspension Compared with Pin Suspension for Lower Extremity Amputees: Effect on Fit, Activity, and Limb Volume", Archives of physical medicine and rehabilitation, vol. 92(10), pp.1570-1575.

[11] Brunelli, S., Delussu, A. S., Paradisi, F., Pellegrini, R. and Traballesi, M. (2013). "A comparison between the suction suspension system and the hypobaric Iceross Seal-In $®$ X5 in transtibial amputees", Prosthetics and Orthotics Internationa, vol. 37(6), pp.436-444.
[12] Dietzen, C. J., Harshberger, J. and Pidikiti, R. D. (1991). "Suction Sock Suspension for Above-Knee Prostheses", JPO Journal of Prosthetics \& Orthotics, vol. 3(2), pp.90-93.

[13] Gholizadeh, H., Azuan, N., Osman, N. A. A., Eshraghi, A., Ali, S., Sævarsson, S. K., Abas, W. A. B. W. and Pirouzi, G. H. (2012). "Transtibial prosthetic suspension: Less pistoning versus easy donning and doffing", Journal of Rehabilitation Research \& Development, vol. 49(9), pp.13211330.

[14] Eshraghi, A., Azuan, N., Osman, N. A. A., Gholizadeh, H., Ahmadian, J. and Rahmati, B. (2013). "Development and Evaluation of New Coupling System for Lower Limb", Science Reports, vol. 3(2270).

[15] Cantamessa, M., Montagna, F. and Cascini, G. (2016). "Design for innovation - A methodology to engineer the innovation diffusion into the development process", Computers in Industry, vol.75(C), pp.46-57.

[16] Ziegler-Graham, K., Mackenzie, E. J., Ephraim, P. L., Travison, T. G., Brookmeyer, R. (2008). "Estimating the Prevalence of Limb Loss in the United States: 2005 to 2050", Archives of Physical Medicine and Rehabilitation, vol. 89(3), pp.422429. 